\title{
Pregnancy after allogeneic hematopoietic stem cell transplantation in a Fanconi anemia patient
}

This article was published in the following Dove Press journal:

International Medical Case Reports Journal

10 January 2017

Number of times this article has been viewed

\section{Simin Atashkhoei \\ Solmaz Fakhari \\ Eissa Bilehjani \\ Haleh Farzin}

Department of Anesthesiology, Al-Zahra Hospital, Tabriz University of Medical Sciences, Tabriz, Iran
Correspondence: Solmaz Fakhari Department of Anesthesiology, Al-Zahra Hospital, Tabriz University of Medical Sciences, Tabriz 5138663 134, Iran Tel +98 914 4024929

Email solmaz_fakhari@yahoo.com
Abstract: Pregnancy in patients with Fanconi anemia (FA) is rare. However, there are reports of successful pregnancy in Fanconi patients after bone marrow transplantation (BMT, hematopoietic stem cell transplantation). We describe the case of a term pregnant woman with FA who was treated with BMT 2 years earlier. She underwent successful delivery with cesarean section using spinal anesthesia without any complications.

Keywords: Fanconi anemia, bone marrow transplantation, pregnancy, cesarean section, spinal anesthesia

\section{Introduction}

Fanconi anemia (FA) is a familial autosomal recessive disorder that occurs due to chromosome fragility, which is generally associated with various congenital and hematological anomalies. FA can be inherited in an autosomal recessive manner, an autosomal dominant manner (RAD51-related FA), or an X-linked manner (FANCBrelated FA). ${ }^{1,2}$ Pregnancy is an uncommon event in patients with FA, since pregnancy in FA is associated with maternal and fetal risks. ${ }^{3}$ Limited data exist on anesthetic management of patients with FA history. In the literature, ${ }^{4}$ there are very few reports about successful pregnancy after allogenic transplantation in FA patients. Morris, ${ }^{5}$ in 2007, reported the first successful pregnancy in a patient with FA who had been transplanted in the prepubertal period with preserved fertility. A detailed literature survey did not reveal any report of anesthesia management in patients with FA undergoing cesarean section $(\mathrm{C} / \mathrm{S})$. Here, we discuss the anesthesia management of a term pregnant woman undergoing $\mathrm{C} / \mathrm{S}$ with a history of bone marrow transplantation (BMT) due to FA.

\section{Case report}

A 24-year-old woman in the 38th week of pregnancy was referred to Department of Gynecology, Al-Zahra Hospital for C/S due to a fetal breech presentation. The patient had been diagnosed with FA 7 years earlier. She underwent allogenic BMT 2 years earlier from her brother, who had been the bone marrow donor. She had one healthy brother, and this disease had not affected the other members of her family.

She had no other complaints other than anemia. On physical examination, she had short stature $(143 \mathrm{~cm})$, skin pigmentation, flat palms and feet, and borderline midpelvis size with prominent ischial spines. She was conscious and oriented. Vital signs were stable, and auscultation of the heart and lungs was normal. Her face was relatively edematous, and the Mallampati score was II to III. Laboratory test results were as 
follows: hemoglobin $(\mathrm{Hb})=10.6 \mathrm{~g} / \mathrm{dL}$, hematocrit $(\mathrm{Hct})=$ $32 \%$, white blood cells (WBC) count $=10,430 / \mathrm{mm}^{3}$, platelet count $=156,000 / \mathrm{mm}^{3}$, international normalized ratio (INR) $=1.1$, prothrombin time $(\mathrm{PT})=12.6$ seconds, plasma blood urea nitrogen $(\mathrm{BUN})=46 \mathrm{mg} / \mathrm{dL}$ and creatinine $=1.0 \mathrm{mg} /$ $\mathrm{dL}$, bleeding time $=2$ minutes, clotting time $=4$ minutes, blood group $=\mathrm{ORH}^{+}$, and direct bilirubin $=0.1 \mathrm{mg} / \mathrm{dL}$. In ultrasound imaging, an alive and mobile fetus was observed with a heart rate of $120 / \mathrm{min}$, breech presentation, and normal amniotic fluid. In oncologic consultation, only mild anemia was reported, and it was recommended that the delivery should preferably be performed by $\mathrm{C} / \mathrm{S}$.

For the patient, three units of isogroup packed red blood cells (RBCs) were crossmatched, and four units of fresh frozen plasma and five units of platelets were reserved. On the day of the operation, the patient fasted for 6 hours with the starting of an intravenous administration of dextrose containing crystalloid solution. In the operation theater, routine standard monitoring (noninvasive blood pressure, electrocardiogram, and pulse oximetry) was carried out, and basic values were measured. Spinal anesthesia was the chosen technique. The patient was rehydrated with $10 \mathrm{~mL} / \mathrm{kg}$ of Ringer's solution in a 15-minute period before induction of the regional anesthesia. Using an aseptic technique, lumbar puncture was performed at the $\mathrm{L}_{3}-\mathrm{L}_{4}$ intervertebral space in the conventional sitting position by using a Quincke spinal needle $(25 \mathrm{G})$ in the midline direction. Bupivacaine $0.5 \% / 1.8 \mathrm{~mL}$ combined with fentanyl $20 \mu \mathrm{g}$ (total volume = $2 \mathrm{~mL}$ ) was administered intrathecally within 10 seconds. The patient was immediately placed in a supine position by tilting the surgical table $15^{\circ}$ to leftward and her head and feet elevated up to $10^{\circ}$ until the delivery of the neonate.

The patient was given oxygen at the flow rate of 4-6 L/min by face mask. The level of sensory block was assessed using the pinprick sensation method. The level of $\mathrm{T}_{5-6}$ was considered adequate for surgery. Maternal hemodynamic parameters (systolic, diastolic, and mean arterial blood pressures, and heart rate) were measured every 2 minutes up to the delivery of the newborn and then every 5 minutes until the end of the surgery. Ephedrine $5 \mathrm{mg}$ intravenous (IV) was given for any hypotension episode (blood pressure $[\mathrm{BP}]<100 \mathrm{mmHg}$ ). Lost blood volume was in normal limits (estimated $\sim 300-400 \mathrm{~mL}$ ). A healthy male newborn, weighing 3,200 g, was delivered with an Apgar score of 9 and 10 at 1 and 5 minutes of delivery, respectively. Cefazolin $1 \mathrm{~g}$ IV was administered after umbilical cord clamping and continued up to 48 hours, for every 6 hours. No event occurred during the surgery and anesthesia. After the surgery, the patient was transferred to a postanesthesia care unit.
After a complete regression of sensory and motor blockade, the patient was transferred to the intensive care unit (ICU). Twenty-four hours after surgery, the laboratory test results were as follows: $\mathrm{Hb}=10.2 / \mathrm{dL}, \mathrm{Hct}=29 \%, \mathrm{INR}=1.1$, PT $=12.6$ seconds, and other test results were within normal ranges. The patient was discharged from hospital 48 hours after the surgery. The patient gave written informed consent for the use of her data in this case report.

\section{Discussion}

This case was our first experience of anesthesia management in a patient suffering from FA, as it is a rare disease. FA is a genetic disorder that ultimately leads to bone marrow failure. Another inherited bone marrow failure syndrome is Diamond-Blackfan anemia. FA is a recessive autosomal disorder and, in $25 \%$ of cases, it has a sibling risk. Our patient had only one brother ( 27 years old) who had been the bone marrow donor. The prevalence of the disease is $\sim 3$ in $1,000,000 .^{1,3}$ FA is the result of a mutation in various genes ( $\sim 18$ genes) involving a DNA repair process; it is a multisystem disease that primarily affects the stem cell of the $\mathrm{WBC}, \mathrm{RBC}$, and platelets. ${ }^{6}$ The result will be a pancytopenia. This disease was named FA because it was first described by Guido Fanconi, a Swiss pediatrician, in $1927 .^{6}$

The clinical characteristics of FA include congenital and hematological abnormalities. In two-thirds of the patients with FA, congenital abnormalities involve skin pigmentation or café au lait spots (50\%), short height (50\%), thumb hypoplasia or radius anomaly $(40 \%)$, abnormal male gonads (30\%), microcephaly (25\%), eye anomalies $(20 \%)$, renal structural defects $(20 \%)$, low-birth weight (10\%), developmental delay (10\%), hearing and ear anomalies (10\%), and cardiopulmonary defects $(6 \%)$. The most important clinical feature of FA is a hematological concern such as pancytopenia. FA patients vary widely in terms of the onset of pancytopenia. The age of onset of bone marrow failure in patients with FA is highly variable, even among siblings. ${ }^{4,7,8}$

Clinically, some FA patients present with major congenital anomalies, some others with malignancies, and yet others show pancytopenia. However, some individuals with FA have neither physical abnormalities nor bone marrow failure; instead, bleeding, pallor, or recurrent infections are the clinical manifestations of pancytopenia. ${ }^{2}$ A major cause of death in FA is bone marrow insufficiency followed by leukemia and solid tumors. Studies reported variable median survival ages ranging from 14 to 25 years. A large number of patients will progress to cancer, usually acute myelogenous leukemia (AML) and, in $90 \%$ of patients, the course continues to bone marrow failure when they reach the age of 40 years. ${ }^{6-8}$ 
The goals of the treatment of FA are increasing the survival rate, establishing a better quality of life, hemodynamic stabilization, and the treatment of malignant conditions. However, only $50-70 \%$ of patients respond to treatment. BMT, the gold standard treatment, is an approach that is associated with elevated graft-versus-host disease (GVHD) and squamous cell carcinoma (SCC). ${ }^{4,6}$

Endocrinopathies such as hypothyroidism, impaired glucose tolerance or overt diabetes mellitus, hyperinsulinemia, and subnormal response to growth hormone stimulation frequently occur in patients with FA.,

Pregnancy is uncommon in nontransplanted FA patients. ${ }^{10}$ The posttransplant fertility rate is extremely low. ${ }^{11}$ These patients are usually affected by infertility due to secondary amenorrhea, an ovulatory menstruation cycle or premature menopause. If fertility occurs, it can be complicated by abortion, maternal transfusion, and preeclampsia with high cesarean delivery rate. Pathophysiology of the ovarian failure is unknown, and no documented study on its histopathology has been published. ${ }^{9}$ Nabhan et al, ${ }^{12}$ in a multicenter retrospective study of 387 transplanted FA patients, identified 202 females who had hematopoietic stem cell transplantation (HSCT) at a median age of 10.5 years. Five of them became pregnant after the HSCT procedure, and one of them had become pregnant twice. ${ }^{12}$

In the largest multicenter European retrospective study on pregnancy outcomes after stem cell transplantation (autologous or allogeneic) in 37,362 transplant patients, the rate of conception was $0.6 \% \cdot{ }^{13}$ But the true incidence of pregnancy after transplantation is unknown. ${ }^{12}$

Patients with FA may undergo various procedures such as Hickman catheter insertion for BMT, limb reconstructive surgery, splenectomy or gastrointestinal surgery, and repair of congenital heart defects. ${ }^{4}$ Dogan et al ${ }^{1}$ reported a 2.5 -year-old girl with FA who needed surgery because of a hip dislocation. They induced general anesthesia with $8 \%$ sevoflurane in $100 \%$ oxygen without $\mathrm{N}_{2} \mathrm{O}$ and then performed caudal epidural block. Intra- and postoperative periods were uneventful. ${ }^{1}$

A possible anesthetic consideration may include the avoidance of high inspired oxygen concentrations $\left(\mathrm{FiO}_{2}\right)$. These patients may be more sensitive to oxygen-free radicals or ionizing radiation. ${ }^{1}$ Dogan et al ${ }^{1}$ preferred using caudal anesthesia, thus avoiding $\mathrm{N}_{2} \mathrm{O}$, reduction of the amount of anesthetic and analgesic agent, and the provision of postoperative analgesia. Kotera et a ${ }^{14}$ reported a case of elective $\mathrm{C} / \mathrm{S}$ in an aplastic anemia patient. They first corrected thrombocytopenia by platelet concentrate transfusion (from $23 \times 10^{3} / \mathrm{mm}^{3}$ to $81 \times$ $10^{3} / \mathrm{mm}^{3}$ ), then performed spinal anesthesia. The delivery was done without any complications. ${ }^{14}$ They suggested that $\mathrm{C} / \mathrm{S}$ is a safe method of delivery in patients with uncontrolled aplastic anemia that can be performed under spinal anesthesia. Spinal anesthesia should be done only when the platelet count is $>50$ $\times 10^{3} / \mathrm{mm} \cdot{ }^{14}$ Evaluation of the hematocrit and platelet count before surgery was essential in Kotera et al's recommendation, however, our patient's platelet count was within the safe range $\left(156 \times 10^{3} / \mathrm{mm}^{3}\right)$. Abnormal upper-limb anatomy may affect the anesthetic procedure. It is probably best that the IV lines and noninvasive blood pressure cuff should be placed on the lower limbs. As the placement of the arterial line in the radial artery may be difficult and may cause increased complications, it is best to be avoided. ${ }^{1}$ Similarly, regional blockade of the upper limbs must be performed with caution. Attention to aseptic technique is important for any invasive procedure, especially in neutropenic cases. ${ }^{15}$

General anesthesia should be planned and preferred in any case of deranged hematological status such as thrombocytopenia and young age group. More than usual bleeding can be expected during the procedure due to thrombocytopenia.

Nitrous oxide-induced bone marrow suppression may be an additional concern. Many investigations suggest that the use of $\mathrm{N}_{2} \mathrm{O}$ may be harmful because of the induced bone marrow suppression. $\mathrm{N}_{2} \mathrm{O}$ impairs methionine synthase activity, disturbs folate metabolism, and thus vitamin B12 metabolism. ${ }^{16}$ In addition to this, there is not enough data on $\mathrm{N}_{2} \mathrm{O}$ safety in patients with FA. ${ }^{1}$

Anesthesia management in these patients involves the following steps:?

1. Preoperative evaluation and preparation (airway examination, assessment of systemic, hematologic, cardiopulmonary, and endocrinal problems).

2. Documentation of all transfusion history and any transfusion-related reaction.

3. Use of leukocyte-free blood products in patients who are candidates for BMT due to the lowering of anti-human leukocyte antigen (HLA) reactions.

4. Close asepsis maintenance by applying antibacterial and viral filters in the anesthesia circuit.

5. Avoidance of drugs and chemical agents that result in bone marrow (BM) toxicity such as chloramphenicol, sulfonamides, nonsteroidal anti-inflammatory drugs (NSAIDs), antithyroid agents, antiepileptics, gold and allopurinol. Avoiding drugs that interact with platelet function in thrombocytopenic patients (e.g., aspirin, antihistamines, and NSAIDs).

6. Avoidance of high inspiratory oxygen concentration. 
7. Avoidance of $\mathrm{N}_{2} \mathrm{O}$ for the maintenance of anesthesia due to its suppressive effect on BM.

8. Short duration of surgery.

In summary, our patient had undergone the related BMT 2 years earlier. Her current problems were short height, some degree of anatomical anomalies, and mild anemia. She had no abnormality in coagulation or of other involved organs. Spinal anesthesia with a low dose of bupivacaine was chosen, and cesarean delivery was performed in a safe manner for mother and baby.

\section{Conclusion}

For the anesthetic management in an FA patient undergoing $\mathrm{C} / \mathrm{S}$ without coagulopathy, we preferred spinal anesthesia to avoid $\mathrm{N}_{2} \mathrm{O}$ effects on bone marrow, to reduce consumption of anesthetic agents, and the possibility of difficult intubation due to facial edema during general anesthesia.

\section{Disclosure}

The authors report no conflicts of interest in this work.

\section{References}

1. Dogan Z, Yildiz H, Coskuner I, Uzel M, Garipardic M. Anesthesia for a patient with Fanconi anemia for developmental dislocation of the hip: a case report. Rev Bras Anestesiol. 2014;64(3):201-204.

2. Mehta PA, Tolar J. Fanconi Anemia. Synonym: Gene Reviews. Seattle: University of Washington; 2016.
3. Alter BP, Frissora CL, Halpéirin DS, et al. Fanconi's anaemia and pregnancy. Br J Haematol. 1991;77(3):410-418.

4. Jacob R, Venkatesan T. Anesthesia and Fanconi anemia: a case report and review of literature. Pediatr Anaesth. 2006;16(9):981-985.

5. Morris ES. Two natural pregnancies following allogeneic transplantation for Fanconi anaemia. Br J Haematol. 2008;140(1):113-119.

6. Goswami M, Bhushan U, Goswami M. Dental perspective of rare disease of Fanconi anemia. Clin Med Insights Case Rep. 2016;9:25-30.

7. Umbarkar S, Iyer H, Ambi U. Anaesthetic management of a patient of Fanconi's anaemia. Bombay Hosp J. 2010;52(3):397-399.

8. Eiler ME, Frohnmayer D, Frohnmayer L, Larsen K, Owen J. Fanconi Anemia: Guidelines for Diagnosis and Management. Third ed. 2008. Available from: http://fanconi.org/images/uploads/other/Chapter_3_ Guidelines_4th_Edition.pdf. Accessed November 10, 2016.

9. Dalle JH, Champagne MA, Duval M. Pregnancy after bone marrow transplantation in Fanconi anaemia. Br J Haematol. 2007;137(1):76.

10. Yabe H, Koike T, Shimizu T, et al. Natural pregnancy and delivery after unrelated bone marrow transplantation using fludarabine-based regimen in a Fanconi anemia patient. Int J Hematol. 2010;91(2): 350-351.

11. Goi K, Sugita K, Nakamura M, et al. Natural pregnancy and delivery after allogeneic bone marrow transplantation in a Fanconi anaemia patient. Br J Haematol. 2006;135(3):408-417.

12. Nabhan SK, Bittencourt M, Duval M, et al. Pregnancy after allogeneic hematopoietic stem cell transplantation in Fanconi anemia patients. Blood. 2008;112(11):456.

13. Salooja N, Szydlo RM, Socié G, et al. Pregnancy outcomes after peripheral blood or bone marrow transplantation: a retrospective survey. Lancet. 2001;358(9278):271-276.

14. Kotera A, Miyazaki N, Hashimoto M, Kouzuma S, Taki K, Esaki K. Anesthetic management of the cesarean section in a patient with aplastic anemia. Masui. 2010;59(6):776-779.

15. Johnston SJ, Bösenberg AT. Fanconi's anaemia and anaesthesia. South Afr J Anaesth Analg. 2004;10(3):9-12.

16. Banks A, Hardman JG. Nitrous oxide. Cont Educ Anaesth Crit Care Pain. 2005;5(5):145-148.
International Medical Case Reports Journal

\section{Publish your work in this journal}

The International Medical Case Reports Journal is an international, peer-reviewed open-access journal publishing original case reports from all medical specialties. Previously unpublished medical posters are also accepted relating to any area of clinical or preclinical science. Submissions should not normally exceed 2,000 words or

\section{Dovepress}

4 published pages including figures, diagrams and references. The manuscript management system is completely online and includes a very quick and fair peer-review system, which is all easy to use. Visit $\mathrm{http}: / /$ www.dovepress.com/testimonials.php to read real quotes from published authors. 